\title{
Risk Tolerance, Impulsivity, and Self-esteem: Differences and Similarities between Gamblers and Non-Gamblers in a Pilot Study
}

\author{
Victoria Suen \\ Department of Psychiatry, Faculty of Medicine, University of Alberta, Edmonton, Canada \\ Matthew R.G. Brown \\ Department of Psychiatry, Faculty of Medicine, University of Alberta, Edmonton, Canada
}

\author{
Randall K. Morck \\ Department of Finance and Statistical Analysis, Faculty of Business, University of Alberta, \\ Edmonton, Canada
}

\section{Ivor Cribben}

Department of Finance and Statistical Analysis, Faculty of Business, University of Alberta, Edmonton, Canada

Peter H. Silverstone

Department of Psychiatry, Faculty of Medicine, University of Alberta, Edmonton, Canada

\begin{abstract}
Risk-taking ranges from socially beneficial entrepreneurship through games of chance as entertainment to problem gambling that can be both individually and socially destructive. There are many conflicting theories about what leads individuals to become gamblers, although some consensus suggests a link to personality traits. Links between gambling and impulsivity, risk tolerance and self-esteem remain unclear, and childhood experiences may be pertinent. To explore these issues, we studied 41 non-gamblers and compared them to 16 individuals identified as frequent gamblers in which both groups completed a psychological battery. The study goal was to try and determine which measures best relate to high propensities towards gambling, particularly with regards to different domains of risk tolerance. In this small sample, the results show the gamblers to have statistically significantly greater financial, recreational and social risk tolerance, as well as higher impulsivity and more favorable attitudes towards gambling overall. In contrast, there were no statistically significant differences in self-esteem and adverse childhood experiences. Multivariate models reveal three measures of risk tolerance to significantly contribute to gambling propensity. While differences in impulsivity exist to some degree, those for self-esteem and adverse childhood experiences were less important. This preliminary research suggests that risk tolerance may be a key psychological determinant in gamblers, but this relatively small study does not support previous suggestions that impulsivity, low self-esteem, or adverse childhood experiences are as important. Repeated studies with larger samples may help further clarify these findings.
\end{abstract}

Keywords: gambling, risk-tolerance, impulsivity, self-esteem, attitudes

\section{INTRODUCTION}

An old New England adage holds that "it was a brave man who first ate a lobster", an example of socially advantageous risk-taking. Individuals' dangerous risk-taking can augment society's collective stock of knowledge. Economies with more entrepreneurial risk taking are more 
Suen, V., Brown, M. R. G., Morck, R. K., Cribben, I., \& Silverstone, P. H. (2017). Risk Tolerance, Impulsivity, and Self-esteem: Differences and Similarities between Gamblers and Non-Gamblers in a Pilot Study. Advances in Social Sciences Research Journal, 4(4) 173-186

prosperous (Fogel, Morck, \& Yeung, 2008; King \& Levine, 1993). However, a propensity to gamble that is innate, at least to some individuals, also explains the continued profitability of casinos, bingo halls, video lottery terminals; VLTs, online gambling and sports betting (Smith, 2013), as well as many investors' betting excessively on single stocks (Goetzmann \& Kumar, 2008; Statman, 2004). While for most individuals this type of gambling is relatively harmless, for others gambling can sometimes have severe detrimental outcomes. With the release of the new Diagnostic and Statistical Manual of Mental Disorders (DSM-5) (American Psychiatric Association, 5th Edition, 2013) the reclassification of gambling disorder (formerly pathological gambling) from an "Impulse-Control Disorder" to a "Substance-Related and Addictive Disorder", suggests that gambling is a type of addiction, similar to drug or alcohol abuse (Petry et al., 2013).

With the recent resurgence in popularity of gambling as a form of legalized entertainment problem gambling has become an increasing area of research (historically lotteries, horse racing, dog racing, etc. were all immensely popular from at least the 1500's on in Europe) (Walker, 1999). Factors repeatedly studied include demographic characteristics (Rahman et al., 2012; Volberg, 1994), risk factors/onset (Burge, Pietrzak, \& Petry, 2006; Rahman, et al., 2012; Yip et al., 2011), and treatment options (Leung \& Cottler, 2009; Petry, 2002). Despite this research, there remain conflicting hypotheses regarding the links between gambling and psychological factors, including risk tolerance, impulsivity, self-esteem, and a possible link to adverse childhood experiences. We wished to examine all of these factors in gamblers compared to controls.

With increasing suggestions that gambling is similar to addictions and that risk tolerance changes are seen in those with addictions (Baler \& Volkow, 2011), it is useful to further examine risk tolerance as a possible contributing factor in gambling. Previous studies in this area have had mixed results, with some finding physiological evidence of risk tolerance in gamblers compared to non-gamblers (Griffiths, 1993), while others find no such evidence (Coventry \& Norman, 1997). Including more than one measure of risk tolerance may help clarify this issue and determine in what areas risk differences between gamblers and nongamblers may exist. Elucidating the differences in risk tolerance while also considering different domains of risk is important to determining where gamblers may be at increased risk for developing problems or making more risky and potentially detrimental decisions outside of the financial realm. Furthermore, to our knowledge, there have been no previous studies examining whether or not risk tolerance in gamblers in the financial domain expands to other domains such as health, social, recreational and ethical risk tolerance.

Several studies have suggested that the psychological factor of impulsiveness is linked to various addictions including alcohol and drugs (Cloninger, Sigvardsson, \& Bohman, 1988; Luengo, Carrillo-de-la-Pena, Otero, \& Romero, 1994; Verdejo-Garcia, Lawrence, \& Clark, 2008), but studies of a possible relationship between impulsiveness and gambling have been much more mixed. Thus, some studies have found that, compared to controls, gamblers have high levels of impulsivity (Blasczcynski, Steel, \& McConaghy, 1997; Carlton \& Manowitz, 1994; Castellani et al., 1996; McCormick, Taber, Kruedelbach, \& Russo, 1987; Nower, Derevensky, \& Gupta, 2004; Steel \& Blaszczynski, 1998), while others have shown that gamblers do not differ, or even have lower levels of impulsivity than controls (Allcock \& Grace, 1988; Blaszczynski, McConaghy, \& Frankova, 1990; Blaszczynski, Wilson, \& McConaghy, 1986; Dickerson, Hinchy, \& Fabre, 1987). These contradictory findings are further complicated by the fact that in many 
studies the gamblers were also substance abusers, while some studies failed to report on history of substance abuse, which may itself have an effect on impulsivity scores. Others have suggested that pathological gambling and substance abuse can have an additive effect on scores of impulsiveness (Petry, 2001; Petry \& Casarella, 1999). Controlling for substance abuse may help clarify the role of personal impulsivity in problem gambling.

Theories of low self-esteem in gamblers stem from the belief that gambling holds many similarities to addictions, whereby addictive behavior is preceded by feelings of low self-worth and elicits temporary relief of these negative thoughts through pleasurable experience (Brown, 1993; Jacobs, 1993; Rosenthal, 1993). Other potentially addicting behaviors, such as the now named Internet Gaming Disorder in DSM-5, have also been linked to lower levels of self-esteem (Niemz, Griffiths, \& Banyard, 2005), providing support that gamblers may also suffer from lower levels of self-esteem. In contrast, others have posited that gamblers may experience high levels of self-esteem as they view themselves as highly skilled in their gambling device of choice (Kusyszyn \& Rutter, 1985). This hypothesis may be correct when looking only at domain-specific self esteem; however, global self-esteem encompasses more than just gambling skills.

Adverse childhood experiences were the focus of a major study by Felitti et al. (1998) on overall mental and physical well-being. They found that higher levels of childhood adversity might account for as much as one-half to two-thirds of drug abuse as well as increased likelihood for experiencing mental health disorders such as depression and hallucinations (Felitti et al., 1998). It follows that increased levels of childhood adversity may lead to lower levels of self-esteem and may also increase risk of developing gambling disorder. To our knowledge, this is the first study to examine possible links between these three.

To help clarify some of these issues, particularly as pertains to different domains of risk tolerance, we carried out a study comparing gamblers with healthy controls in order to examine any psychological differences between the two populations. Based upon the literature, we had several hypotheses we wished to examine:

1. Gamblers would endorse more positive gambling related attitudes, and that there would be a significant correlation between gambling measures.

2. Gamblers would report higher levels of risk tolerance. We hypothesized that this increased risk tolerance would encompass not only financial risk but other domains of risk as well.

3. In gamblers who did not have substance abuse issues, there would be no association with impulsiveness.

Gamblers would report lower levels of self-esteem, potentially linked to a greater report of traumatic experiences as a child. We also expected risk tolerance to be positively correlated with adverse childhood experiences.

\section{Participants and Procedure}

\section{METHODOLOGY}

Participants were recruited from the University of Alberta campus and surrounding area via online advertising. The study was approved by the University of Alberta Health Research Ethics Board. Following completion of informed consent, all participants were screened for the presence of psychiatric disorders and ongoing alcohol or drug abuse using standardized 
Suen, V., Brown, M. R. G., Morck, R. K., Cribben, I., \& Silverstone, P. H. (2017). Risk Tolerance, Impulsivity, and Self-esteem: Differences and Similarities between Gamblers and Non-Gamblers in a Pilot Study. Advances in Social Sciences Research Journal, 4(4) 173-186

questionnaires. Any individuals who had ongoing alcohol or drug abuse were excluded from further participation. Participants then completed the Problem Gambling Severity Screen (PGSI; (Ferris \& Wynne, 2001) and a psychological battery consisting of the Gambling Attitudes and Beliefs Scale (GABS; (Breen \& Zuckerman, 1994), two measures of risk tolerance (Grable \& Lytton, 1999; Weber, Blais, \& Betz, 2002), the Barratt Impulsivity Scale (BIS-11; (Patton, Stanford, \& Barratt, 1995) and the Rosenberg Self-Esteem Scale (Rosenberg, 1965); and the Adverse Childhood Experiences Scale (Felitti et al., 1998). Those individuals who scored higher on the PGSI (see Gambling section below for details) were characterized as gamblers, while those who scored lower formed the healthy control group.

A total of 57 individuals entered the study (mean age 25.4 \pm 5.32 years, range: 20-48 years) of which $70.2 \%$ were male. Based on the scores on the PGSI, there were 41 individuals in the Control group and 16 individuals in the "Gambler" group. The "Gamblers" exhibited a variety of preferred forms of gambling, including attending casinos regularly, playing internet poker frequently, and betting on sport outcomes, while some reported regularly engaging in a mixture of gambling forms.

\section{Measurements Used}

Cronbach's alpha $(\alpha)$ is reported for each scale and is a measure of internal reliability which ranges from zero to one. The closer the score is to one, the greater is the internal reliability.

\section{Gambling.}

The PGSI (Ferris \& Wynne, 2001) was used to determine gambling behavior among participants. For this screening tool, participants were asked to think about the last 12 months and answer nine questions (e.g. Have you bet more than you could really afford to lose?; $\alpha=$ .913) from 0 (never) to 3 (almost always). Responses for all questions were summed for a total scale score of problem gambling and used to separate participants into either the control (total scores 0-2) or "Gambler" group (total scores $>3$ ). Based on Ferris and Wynne's (Ferris \& Wynne, 2001) report, total scores of 3-7 indicate a moderate level of problems due to gambling, leading to some negative consequences, with higher scores (8 - 27) indicating greater severity of problems. Thus in this study, those who scored 3 or more were grouped to form our gambling group, while those who scored less than 3 formed the control group.

Additionally, participants also completed Breen and Zuckerman's (1994) Gambling Attitudes and Beliefs Scale (GABS) to assess overall gambling-related attitudes. Participants were asked to rate how much they agreed with 35 statements regarding gambling (e.g. There is no way I can know if I will have good or bad luck) from 1 (strongly agree) to 4 (strongly disagree). The GABS was scored as the sum of all items, with higher total scores indicating greater endorsement of pro-gambling attitudes and beliefs $(\alpha=.908)$.

\section{Risk Tolerance}

Two measures of risk tolerance were administered. Grable and Lyttons'(1999) 13-item scale was used to determine financial risk tolerance. In this, participants were asked a series of financially-related questions (e.g. In terms of experience, how comfortable are you investing in stocks or stock mutual funds?) with multiple-choice answers, each given a score from 1-4 during analysis based on how risky tolerant the chosen response was ( 1 - least risky choice, 4 - Most risky choice). Responses were divided into three subscales: Investment Risk (five items), Risk Comfort and Experience (five items), and Speculative Risk (3 items). Overall risk 
tolerance was scored as the sum of all responses $(\alpha=.698)$ ranging from $0-52$. Higher scores reflect greater risk tolerance.

Participants also completed Weber, Blais, and Betz's (2002) 30-item Domain-Specific RiskTaking (DOSPERT) Scale. This measure asked participants to rate willingness to participate in risky activities as well as asking them to give their overall risk perception of those activities from 1 (extremely unlikely) to 7 (extremely likely). Scores were calculated by summing the responses. Higher scores on the willingness to participate scale indicate greater likelihood to engage in the activity, and higher scores for the perception of risk scale indicate higher perceived risk of the activity. The DOSPERT assesses both levels of risk in five domains: ethical (e.g. Having an affair with a married man/woman; $\alpha$ 's $=.773$ for willingness to participate and .705 for perception of risk), financial (e.g. Betting a day's income at the horse races; $\alpha$ 's $=.772$ for willingness to participate and .773 for perception of risk), health safety (e.g. Drinking heavily at a social function; $\alpha$ 's $=.753$ for willingness to participate and .820 for perception of risk), social (e.g. Admitting that your tastes are different from those of a friend; $\alpha$ 's $=.571$ for willingness to participate and .695 for perception of risk), and recreational (e.g. Going down a ski run that is beyond your ability; $\alpha$ 's $=.839$ for willingness to participate and .783 for perception of risk).

\section{Impulsivity}

Participants completed the 30-item Barratt Impulsivity Scale (BIS-11; (Patton, et al., 1995) to assess impulsivity. Participants we asked to rate how likely they would be to act or think in different situations (e.g. I do things without thinking) from 1 (Rarely/Never) to 4 (Almost Always/Always). Responses were summed to obtain scale scores for three second-order factors (Attentional Impulsiveness; 8 items, Motor Impulsiveness; 11 items, Nonplanning Impulsiveness; 11 items) as well as an overall scale score. Higher scores indicate higher levels of impulsivity $(\alpha=.747)$.

\section{Self-esteem}

Self-esteem was measured using Rosenberg's (1965) ten-item scale. Participants were asked to rate their general feelings about themselves (e.g. On the whole, I am satisfied with myself) from 0 (Strongly Disagree) to 3 (Strongly Agree). Responses were summed to obtain self-esteem score (0-30), with a higher score indicating a higher level of self-esteem $(\alpha=.842)$.

\section{Childhood trauma}

Participants completed the ten-item scale from the Adverse Childhood Experience (ACE) Study (Felitti et al,. 1998) to determine presence of trauma during the participant's younger life. Participants were asked to indicate whether or not a list of events took place within the first 18 years of life (e.g. Did you live with anyone who was a problem drinker or alcoholic or who used street drugs?). 'Yes' answers were summed to provide a total score (0-10), with a higher score indicating a higher level of adverse childhood experiences $(\alpha=.666)$.

\section{Statistical measurements}

One-sample Kolmogorov-Smirnov tests were run on all scales to test for normality. Based on these results logarithmic transformations were conducted for financial risk tolerance subscales and total score, as well for the DOSPERT (willingness to participate) subscales. One-sample Kolmogorov-Smirnov tests were rerun on the transformed data to ensure normality. Independent samples t-tests were run on the demographics, analysis of covariance (ANCOVA) tests were conducted for all the scales (Table 1), and multiple linear regression was conducted to determine which measures predicted gambling severity as measured by the PGSI (Table 3) 
Suen, V., Brown, M. R. G., Morck, R. K., Cribben, I., \& Silverstone, P. H. (2017). Risk Tolerance, Impulsivity, and Self-esteem: Differences and Similarities between Gamblers and Non-Gamblers in a Pilot Study. Advances in Social Sciences Research Journal, 4(4) 173-186

and GABS (Table 4). The assumptions of the multiple linear regression model were checked and verified.

\section{RESULTS}

In terms of differences between the participants in the two groups, there were no statistically significant differences between controls and "Gamblers" in terms of age $(t(55)=-1.953, p=$ $0.056)$, gender $(t(55)=1.135, p=0.261)$, or ethnicity $(t(55)=1.691, p=0.097)$. However, there were statistically significant demographic differences between the two groups in terms of level of education $(t(55)=2.951, p=0.005)$, with controls reporting higher level of education than gamblers. Two-way ANOVA analyses were computed to determine if level of education had any interaction effects with the psychological scales. There were main effects for the BIS-11 Nonplanning Impulsiveness subscale $(F(2,55)=3.438, p=0.039)$, PGSI $(F(2,55)=6.850, p=$ $0.002)$ and the DOSPERT Ethical subscale $(F(2,55)=4.720, p=0.013)$. Level of education was negatively correlated with all three measures $(r=-0.287, p=0.031 ; r=-0.427, p=0.001$; and $r$ $=-0.372, p=0.004$, respectively).

As would be anticipated, there were significant differences between the two groups in the GABS, with "Gamblers" scoring higher than controls (Table 1). Controlling for level of education, significant differences were found between groups on the PGSI (Table 1). There was also a highly significant $(p<0.01$ ) correlation between our two gambling measures (Table 2 ).

"Gamblers" and controls differed significantly on overall financial risk tolerance with "Gamblers" scoring higher than controls (Table 1). When examining the three subscales separately, significant differences were seen only in the Risk Comfort and Experience scale score. DOSPERT scores were significantly different in two domains: Financial and Health Safety. In both domains, "Gamblers" scored higher than controls. Interestingly, across all domains, there were no significant differences in perception of risk (Table 1).

Significant differences between the groups emerged in the BIS-11 Motor Impulsiveness subscale, with "Gamblers" scoring higher than controls (Table 1). No significant differences emerged on the BIS-11 subscales of Attentional Impulsiveness, Non Planning Impulsiveness, or the total impulsiveness score. A correlation analysis determined that impulsivity was partially linked to the gambling measures: total BIS-11 score, as well as subscales Motor Impulsiveness and Non Planning Impulsiveness, were positively correlated with both the GABS and PGSI (Table 2).

No significant differences were found between groups in adverse childhood experiences or in self-esteem, after controlling for education (Table 1). Utilizing a correlational analysis, a negative association was found between the two scales (Table 2): Financial risk tolerance as measured by Grable and Lyons' (1999) scale was correlated with adverse childhood experiences (Table 2).

To determine to what extent the psychological measures collected related to gambling severity, two regressions were performed as measured by both gambling measures: the PGSI and the GABS. When both the PGSI and GABS were regressed against Grable and Lytton's (Grable \& Lytton, 1999) Financial Risk Tolerance Scale, significant relationships did emerge. However, these relationships became insignificant in the presence of the other independent variables. A significant relationship emerged when regressing total BIS score, BIS Nonplanning subscale and BIS Motor Impulsiveness subscale individually with both the PGSI and GABS; however, 
these relationships also became insignificant in the presence of the other independent variables. Significant predictors of PGSI included GABS, Age, and the DOSPERT Health and Safety subscale. These predictors explained $61 \%$ of the variability in PGSI scores (Table 3). Significant predictors of GABS included PGSI, DOSPERT subscales Financial, Recreational, Social and perception of Recreational risk. These predictors explained $68 \%$ of the variability in GABS scores (Table 4).

\section{DISCUSSION}

The purpose of this study was to examine possible psychological differences between gamblers and controls and possible links between these measures. Unfortunately, in this sample we had fewer gamblers than we had anticipated, and therefore the results should be considered only as pilot findings.

Our first hypothesis was that gamblers would endorse more positive gambling-related attitudes and that there would be a significant correlation between the two gambling measures. Our results supported this, and we found that those with the highest gambling scores (referred to as "Gamblers") reported endorsing more positive attitudes and irrational beliefs towards gambling than did controls. Since our "Gamblers" were defined by our screening to possess moderate levels of problems due to gambling, it follows that this group should report higher agreement with pro-gambling statements than controls. Our use of the PGSI as a tool to assign participants was supported by the positive correlation between the two measures of gambling (PGSI and GABS), which was also in line with our expectations.

Our second hypothesis was that gamblers would report higher levels of risk tolerance. Our findings also supported this, since they indicate that there are significant differences between "Gamblers" and controls in terms of risk tolerance, both financially and in other non-financial domains. Specifically, "Gamblers" scored higher on financial risk tolerance, which appears to be driven by their risk comfort and experience. In general, gamblers are more likely to be in a situation where financial risk is a factor, and thus it follows that they should feel more comfortable with experiencing such risk. This supports previous research in which a physiological marker of tolerance (heart rate) was linked to gambling behavior (Griffiths, 1993). In the earlier study, regular gamblers were found to have an immediate and significant decrease in heart rate after gambling than non-regular gamblers. This immediate decrease in heart rate shows how gamblers have physiologically adapted to the experience of financial risk compared to non-gamblers. Coupled with our results, we conclude that it is the experience and increased comfort with financial risk that leads, in part, to the adaptation and increased risk tolerance seen in gamblers.

Differences also emerged in a financially-distinct domain, Health and Safety, in which "Gamblers" reported greater willingness to participate in activities that could be seen as having a greater risk to one's personal health and safety. While these results support our hypothesis that greater risk tolerance is not unique to the financial domain, that associations were not found in all other assessed domains lends support to the argument that risk is not a stable trait (Hanoch, Johnson, \& Wilke, 2006). This is contrary to the previously dominant view in psychology, in which individuals were believed to demonstrate consistent risk taking and attitudes across domains (Eysenck \& Eysenck, 1977; Lejuez et al., 2002). Interestingly, there were no significant differences in perception of risk between the groups. That is, "Gamblers" and controls rated the activities/behaviors similarly in terms of perception of risk. "Gamblers", who reported more willingness to engage in higher risk behaviors, did not view these behaviors as less risky than did the controls. In fact, despite the high risk present, these individuals would still be more likely to participate in the behaviors. These results expand on 
Suen, V., Brown, M. R. G., Morck, R. K., Cribben, I., \& Silverstone, P. H. (2017). Risk Tolerance, Impulsivity, and Self-esteem: Differences and Similarities between Gamblers and Non-Gamblers in a Pilot Study. Advances in Social Sciences Research Journal, 4(4) 173-186

gambler's tendencies towards higher risk and demonstrate that these occur not only in financial scenarios. Gamblers do perceive higher risk situations similar to non-gamblers; however, recognizing this risk does not produce the same deterring effect that is achieved in non-gamblers. Rather, in addition to the anticipated monetary gains, gamblers appear to seek 'action' in the form of increased excitement or an 'adrenaline rush' when they choose to take financial risk (Lesieur \& Rosenthal, 1991). This 'action' has been suggested as being similar to the euphoric state that drug addicts seek and supports previous researchers who have likened gambling to substance based addictions (Levinson, Gernstein, \& Maloff, 1983; Moran, 1970, Petry et al., 2013).

Our third hypothesis was that, in gamblers who did not have substance abuse issues, there would be no association with impulsiveness. However, the findings were contrary to our hypothesis, and significant differences emerged for impulsivity between the groups. Differences were found for the motor impulsiveness subscale, with "Gamblers" reporting greater impulsiveness than controls. This subscale refers to items such as "I do things without thinking" and "I act on the spur of the moment". Thus. "Gamblers" reported greater impulsivity regarding actions. It has been suggested that there are two facets of impulsivity: reward-driven (a goal-focused approach behavior) and rash (an individual's inability to halt approach behavior) impulsivity (Dawe \& Loxton, 2004). In the case of gambling, rash impulsivity refers to gambling in spite of knowing the potential punishments. Previous research has implicated impulsivity with gambling in both men and women (Loxton, Nguyen, Casey, \& Dawe, 2008), and our results support this finding as rash impulsivity shares similarities with the motor impulsiveness subscale. This rash impulsivity and increased motor impulsiveness may also explain why gamblers' similar perception to non-gamblers of high-risk situations is not a deterrent from engaging in risky behaviors.

It should be noted that overall impulsivity was not significantly different between the groups, although with a larger sample it is conceivable that this result may become significant. As well, we found that all but one subscale (Attentional Impulsiveness) was correlated with both the GABS and PGSI. This is consistent with previous research, which has found correlational links between other measures of impulsivity (specifically Eysenck's Impulsivity scale) and gambling measures (PGSI and Gambling Involvement; (Mishra, Lalumière, \& Williams, 2010). Thus, our results lend support to the argument that impulsivity, or certain aspects of impulsivity at the very least, is related to gambling behavior.

Our fourth hypothesis was that gamblers would report lower levels of self-esteem, potentially linked to a greater report of traumatic experiences as a child. However, this hypothesis was not supported, and we found no statistically significant differences between gamblers and controls for self-esteem or for adverse childhood experiences. Some previous studies have had similar findings, with some finding no relationship between self-esteem and gambling (Volberg, Reitzes, \& Boles, 1997) or between gambling, self-esteem, and addictions overall (Greenberg, Lewis, \& Dodd, 1999). Our results may indicate that rather than gambling acting as a coping mechanism for low self-esteem, it is rather greater willingness to engage in risky behaviors despite the perceived risk that differentiates gamblers to controls. Nonetheless, our results do point to a decrease in self-esteem when there is the presence of childhood traumatic events, which is supported by previous studies that have linked the two (Browne \& Finkelhor, 1986; Low, Jones, MaCleod, Power, \& Duggan, 2000). Based on these results, it appears that neither self-esteem nor traumatic events early in life are differential factors between gamblers and 
non-gamblers. While the ACE study (Felitti et al., 1998) has provided evidence that childhood trauma can have long lasting detrimental health outcomes and has been linked to drug abuse, no evidence has yet been found linking such trauma to the development of gambling disorder.

In terms of the relative importance of each component, GABS score, age, and the Health and Safety DOSPERT subscale significantly explained $60.5 \%$ of the variance in PGSI scores. Interestingly, both financial risk tolerance measures did not significantly contribute to the model in the presence of the other independent variables. However, based on the moderate explanatory power of the model, it is likely that the current measures do not encompass the full picture of problem gambling. The PGSI, DOSPERT Financial, Recreational, Social, and perception of Recreational risk subscales significantly explained $67.7 \%$ of the variability in GABS score. While this model fairs only slightly better than the previous model, it does lend some support to our group comparisons with "Gamblers" endorsing greater risk tolerance in more than just the financial domain. It should be noted that when the PGSI and GABS was regressed against only Grable and Lytton's (1999) Financial Risk Tolerance Scale, a significant relationship did emerge. Thus, there is a significant relationship between risk tolerance and both gambling severity and gambling attitudes; however, other measures produced better explanatory relationships. In keeping with some previous findings (Mishra, et al., 2010), neither gambling measure was significantly predicted by the impulsivity measure in the presence of all independent variables, providing support for the hypothesis that impulsivity may not be the best predictor for gambling nor hold the strongest relationship to gambling. While our sample of gamblers and controls differed on their scores of one subscale of impulsivity (Motor Impulsiveness), this difference is only a predicting factor on reported gambling behavior or attitudes and beliefs when no other variables were included. However, overall impulsivity and the Nonplanning scale individually were also significant predictors of both gambling measures and so impulsivity cannot be completely discounted when discussing gambling disorder. Self-esteem and adverse childhood experiences also failed to be significant in both models.

Post hoc analyses were conducted to determine if age or gender had any significant relationship to our risk tolerance or impulsivity variables. Interestingly, no significant relationships emerged for impulsivity, suggesting that impulsivity remains stable throughout life and between genders. A maturation (age) relationship emerged with both Grable and Lytton's (1999) Financial Risk Tolerance Scale (with age explaining 9.3\% or the variance in financial risk tolerance) and the DOSPERT Social subscale (with age explaining 5.9\% of the variance in the DOSPERT Social subscale) while a gender effect emerged for DOSPERT Ethical perception of risk subscale (with gender explaining $10.5 \%$ of the variance in the DOSPERT Ethical perception of risk subscale). While these predictors all reached significance, they remain relatively weak predictors of the risk tolerance scales thus we conclude that these relationships are not of significant interest or importance.

There are some limitations to our study. The first is that the number of gamblers was small. This finding means that our results need to be replicated in larger studies. Additionally, since they were recruited via the Internet, they may preferentially represent certain groups of gamblers (young, internet gamblers). They were also in the top of the "moderate" range for gambling scores, so individuals with more severe gambling problems may have given a different outcome. Furthermore, although there were no differences in age, sex, or ethnicity between our two groups, there was a difference in education. This difference in level of education was likely due to how our sample was recruited, with many of the controls coming from the University of Alberta while many of our gamblers were recruited from the community. However, it is important to note that while the proportion of university educated 
Suen, V., Brown, M. R. G., Morck, R. K., Cribben, I., \& Silverstone, P. H. (2017). Risk Tolerance, Impulsivity, and Self-esteem: Differences and Similarities between Gamblers and Non-Gamblers in a Pilot Study. Advances in Social Sciences Research Journal, 4(4) 173-186

participants favored the control group, there was still a mix of both university and high school educated individuals in both groups. As well, this difference in level of education was taken into consideration and controlled for in our remaining analyses. In order to test the generalizability of our results, a larger and more varied sample is required.

\section{CONCLUSION}

Gambling disorder shares some commonalities with substance abuse; hence it's reclassification into the same category in the newest edition of the DSM. However, despite much research in the field, there are still conflicting theories on some of the psychological links to gambling. Our results provide support for suggestions that those experiencing gambling problems endorse more positive attitudes and beliefs towards gambling. Our primary finding is that gamblers have greater risk tolerance across multiple domains, not just greater financial risk tolerance, even though they do not have a difference in terms of their risk assessment. Our findings also failed to support previous suggestions that impulsivity significantly explains gambling severity in the presence of other variables or that this is linked to lowered self-esteem or greater rates of adverse childhood experience. The psychological factors, which lead some individuals to change from enjoying gambling as an occasional social activity to one that can have catastrophic personal impacts for that individual, remain uncertain.

\section{FUNDING ACKNOWLEDGEMENT}

This work was supported by the Social Sciences and Humanities Council of Canada [IDG 4302011-0639].

\section{References}

Allcock, C. C., \& Grace, D. M. (1988). Pathological gamblers are neither impulsive nor sensation-seekers. Australian and New Zealand Journal of Psychiatry, 22(3), 307-311.

Association, A. P. (2013). Diagnostic and statistical manual of mental disorders (5th ed.). Arlington, VA: American Psychiatric Publishing.

Baler, R. D., \& Volkow, N. D. (2011). Addiction as a Systems Failure: Focus on Adolescence and Smoking. Journal of the American Academy of Child \& Adolescent Psychiatry, 50, 329-339.

Blasczcynski, A., Steel, Z., \& McConaghy, N. (1997). Impulsivity in pathological gambling: The antisocial impulsivist. Addiction, 92, 75-87.

Blaszczynski, A., McConaghy, N., \& Frankova, A. (1990). Boredom proneness in pathological gambling. Psychological Reports, 67(1), 35-42. doi: 10.2466/pr0.1990.67.1.35

Blaszczynski, A., Wilson, A. C., \& McConaghy, N. (1986). Sensation seeking and pathological gambling. British Journal of Addiction, 81(1), 113-117.

Breen, R. B., \& Zuckerman, M. (1994). The gambling beliefs and attitudes survey. Unpublished instrument. University of Delaware.

Brown, R. I. F. (1993). Some contributions of the study of gambling to the study of other addictions. In W. R. Eadington \& J. A. Cornelius (Eds.), Gambling Behavior and Gambling Problems (pp. 241-272).

Browne, A., \& Finkelhor, D. (1986). Impact of child sexual abuse: A review of the research. Psychological Bulletin, $99,66-77$. 
Burge, A., Pietrzak, R., \& Petry, N. (2006). Pre/Early Adolescent Onset of Gambling and Psychosocial Problems in Treatment-Seeking Pathological Gamblers. Journal of Gambling Studies, 22(3), 263-274. doi: 10.1007/s10899006-9015-7

Carlton, P. L., \& Manowitz, P. (1994). Factors determining the severity of pathological gambling in males. Journal of Gambling Studies, 10(2), 147-157.

Castellani, B., Wootton, E., Rugle, L., Wedgeworth, R., Prabucki, K., \& Olson, R. (1996). Homelessness, negative affect, and coping among veterans with gambling problems who misused substances. Psychiatric Services, 47(3), 298-299.

Cloninger, C. R., Sigvardsson, S., \& Bohman, M. (1988). Childhood personality predicts alcohol abuse in young adults. Alcohol Clin Exp Res, 12, 494-505.

Coventry, K. R., \& Norman, A. C. (1997). Arousal, sensation seeking and frequency of gambling in off-course horse racing bettors. British Journal of Psychology, 88(4), 671-681. doi: 10.1111/j.2044-8295.1997.tb02664.x

Dawe, S., \& Loxton, N. J. (2004). The role of impulsivity in the development of substance use and eating disorders. Neuroscience and Biobehavioral Reviews, 28, 343-351.

Dickerson, M., Hinchy, J., \& Fabre, J. (1987). Chasing, Arousal and Sensation Seeking in Off-course Gamblers. British Journal of Addiction, 82(6), 673-680. doi: 10.1111/j.1360-0443.1987.tb01530.x

Eysenck, S. B., \& Eysenck, H. J. (1977). The place of impulsivness in a dimensional system of personality description. British Journal of Social and Clinical Psychology, 16, 57-68.

Felitti, V. J., Anda, R. F., Nordenberg, D., Williamson, D. F., Spitz, A. M., V., E., ... Marks, J. S. (1998). Relationship of childhood abuse and household dysfunction to many of the leading causes of death in adults: The adverse childhood experiences (ACE) study. American Journal of Preventive Medicine, 14, 245-258.

Ferris, J., \& Wynne, H. (2001). The Canadian Problem Gambling Index: Final Report. Ottawa: Canadian Centre on Substance Abuse.

Fogel, K., Morck, R., \& Yeung, B. (2008). Big business stability and economic growth: Is what's good for General Motors good for America? Journal of Financial Economics, 89(1), 83-108. doi:

http://dx.doi.org/10.1016/j.jfineco.2007.06.004

Goetzmann, W. N., \& Kumar, A. (2008). Equity portfolio diversifivation. Review of Finance, 12, 433-463. Grable, J., \& Lytton, R. H. (1999). Financial risk tolerance revisited: The development of a risk assessment instrument. Financial Services Review, 8, 163-181.

Greenberg, J. L., Lewis, S. E., \& Dodd, D. K. (1999). Overlapping addictions and self-esteem among college men and women. Addictive Behaviors, 24(4), 565-571. doi: http://dx.doi.org/10.1016/S0306-4603(98)00080-X

Griffiths, M. (1993). Tolerance in gambling: An objective measure using the psychophysiological analysis of male fruit machine gamblers. Addictive Behaviors, 18(3), 365-372. doi: http://dx.doi.org/10.1016/03064603(93)90038-B

Hanoch, Y., Johnson, J. G., \& Wilke, A. (2006). Domain Specificity in Experimental Measures and Participant Recruitment: An Application to Risk-Taking Behavior. Psychological Science, 17(4), 300-304. doi: 10.1111/j.14679280.2006.01702.x

Jacobs, D. F. (1993). Evidence supporting a general theory of addiction. In W. R. Eadington \& J. A. Cornelius (Eds.), Gambling Behavior and Problem Gambling (pp. 287-294).

King, R. G., \& Levine, R. (1993). Finance, entrepreneurship and growth. Journal of Monetary Economics, 32(3), 513-542. doi: http://dx.doi.org/10.1016/0304-3932(93)90028-E

Kusyszyn, H. R., \& Rutter, R. (1985). Personality characteristics of male heavy gamblers, light gamblers, nongamblers, and lottery players. Journal of Gambling Behavior, 1, 59-63. 
Suen, V., Brown, M. R. G., Morck, R. K., Cribben, I., \& Silverstone, P. H. (2017). Risk Tolerance, Impulsivity, and Self-esteem: Differences and Similarities between Gamblers and Non-Gamblers in a Pilot Study. Advances in Social Sciences Research Journal, 4(4) 173-186

Lejuez, C. W., Read, J. P., Kahler, C. W., Richards, J. B., Ramsey, S. E., Stuart, G. I., .. Brown, R. A. (2002). Evaluation of a behavioral measure of risk taking: The balloon analogue risk task (BART). Journal of Experimental Psychology: Applied, 8, 75-84.

Lesieur, H., \& Rosenthal, R. (1991). Pathological gambling: A review of the literature (prepared for the American Psychiatric Association task force on DSM-IV committee on disorders of impulse control not elsewhere classified). Journal of Gambling Studies, 7(1), 5-39. doi: 10.1007/BF01019763

Leung, K. S., \& Cottler, L. B. (2009). Treatment of pathological gambling. Current Opinion on Psychiatry, 22, 69-74. Levinson, P. K., Gernstein, D. R., \& Maloff, D. R. (1983). Commonalities in substance abuse and habitual behaviors. Lexington, MA: Lexington Books.

Low, G., Jones, D., MaCleod, A., Power, M., \& Duggan, C. (2000). Childhood trauma, dissociation and self-harming behaviour: A pilot study. British Journal of Medical Psychology, 73(2), 269-278. doi: 10.1348/000711200160363

Loxton, N. J., Nguyen, D., Casey, L., \& Dawe, S. (2008). Reward drive, rash impulsivity and punishment sensitivity in problem gamblers. Personality and Individual Differences, 45(2), 167-173. doi:

http://dx.doi.org/10.1016/j.paid.2008.03.017

Luengo, M. A., Carrillo-de-la-Pena, M. T., Otero, J. M., \& Romero, E. (1994). A shotr-term longitudinal study of impulsivity and antisocial beahvior. Journal of Personality and Social Psychology, 66, 542-548.

McCormick, R. A., Taber, J., Kruedelbach, N., \& Russo, A. (1987). Personality profiles of hospitalized pathological gamblers: The California Personality Invertory. Journal of Clinical Psychology, 43(5), 521-527.

Mishra, S., Lalumière, M. L., \& Williams, R. J. (2010). Gambling as a form of risk-taking: Individual differences in personality, risk-accepting attitudes, and behavioral preferences for risk. Personality and Individual Differences, 49(6), 616-621. doi: http://dx.doi.org/10.1016/j.paid.2010.05.032

Moran, E. (1970). Varieties of pathological gambling. British Journal of Psychiatry, 116, 593-597.

Niemz, K., Griffiths, M., \& Banyard, P. (2005). Prevalence of pathological internet use among university students and correlations with self-esteem, the general health questionnaire (GHQ), and disinhibition. CyberPsychology \& Behavior, 8, 562-570.

Nower, L., Derevensky, J. L., \& Gupta, R. (2004). The Relationship of Impulsivity, Sensation Seeking, Coping, and Substance Use in Youth Gamblers. Psychology of Addictive Behaviors, 18(1), 49-55. doi: 10.1037/0893164x.18.1.49

Patton, J. M., Stanford, M. S., \& Barratt, E. S. (1995). Factor structure of the Barratt Impulsiveness Scale. Journal of Clinical Psychology, 51, 768-774.

Petry, N. (2001). Substance abuse, pathological gambling, and impulsiveness. Drug and Alcohol Dependence, 63(1), 29-38. doi: 10.1016/s0376-8716(00)00188-5

Petry, N. (2002). A Comparison of Young, Middle-Aged, and Older Adult Treatment-Seeking Pathological Gamblers. The Gerontologist, 42(1), 92-99. doi: 10.1093/geront/42.1.92

Petry, N., Blanco, C., Auriacombe, M., Borges, G., Bucholz, K., Crowley, T., ... O’Brien, C. (2013). An Overview of and Rationale for Changes Proposed for Pathological Gambling in DSM-5. Journal of Gambling Studies, 1-10. doi: $10.1007 /$ s10899-013-9370-0

Petry, N., \& Casarella, T. (1999). Excessive discounting of delayed rewards in substance abusers with gambling problems. Drug and Alcohol Dependence, 56(1), 25-32. 
Rahman, A. S., Pilver, C. E., Desai, R. A., Steinberg, M. A., Rugle, L., Krishnan-Sarin, S., \& Potenza, M. N. (2012). The relationship between age of gambling onset and adolescent problematic gambling severity. Journal of Psychiatric Research, 46(5), 675-683. doi: http://dx.doi.org/10.1016/j.jpsychires.2012.02.007

Rosenberg, M. (1965). Society and the adolescents self-image. Princeton NJ: Princeton University Press.

Rosenthal, R. J. (1993). Some causes of pathological gambling. In W. R. Eadington \& J. A. Cornelius (Eds.), Gambling Behavior and Problem Gambling (pp. 143-148).

Smith, G. (2013). The nature and scope of gambling in Canada. Addiction, n/a-n/a. doi: 10.1111/add.12210

Statman, M. (2004). The diversification puzzle. Financial Analysts Journal 60, 44.

Steel, Z., \& Blaszczynski, A. (1998). Impulsivity, personality disorders and pathological gambling severity. Addiction, 93(6), 895-905.

Verdejo-Garcia, A., Lawrence, A. J., \& Clark, L. (2008). Impulsivity as a vulnerability marker for substance use disorders: Review of findings from high-risk research, problem gamblers and genetic addociation studies. Neurosci Biobehav R, 32, 777-810.

Volberg, R. A. (1994). The prevalence and demographics of pathological gamblers: Implications for public health. Am J Public Health, 84, 237-241.

Volberg, R. A., Reitzes, D. C., \& Boles, J. (1997). Exploring the links between gambling, problem gambling, and selfesteem. Deviant Behavior, 18(4), 321-342. doi: 10.1080/01639625.1997.9968065

Walker, J. (1999). Gambling and venetian noblemen c.1500-1700. Past Present, 162, 28-70.

Weber, E. U., Blais, A.-R., \& Betz, N. (2002). A domain-specific risk-attitude scale: Measuring risk perceptions and risk behaviors. Journal of Behavioral Decision Making, 15, 263-290.

Yip, S. W., Desai, R. A., Steinberg, M. A., Rugle, L., Cavallo, D. A., Krishnan-Sarin, S., \& Potenza, M. N. (2011). Health/Functioning Characteristics, Gambling Behaviors, and Gambling-Related Motivations in Adolescents Stratified by Gambling Problem Severity: Findings from a High School Survey. The American Journal on Addictions, 20(6), 495-508. doi: 10.1111/j.1521-0391.2011.00180.x 
Suen, V., Brown, M. R. G., Morck, R. K., Cribben, I., \& Silverstone, P. H. (2017). Risk Tolerance, Impulsivity, and Self-esteem: Differences and Similarities between Gamblers and Non-Gamblers in a Pilot Study. Advances in Social Sciences Research Journal, 4(4) 173-186

Table: 1 Analysis of covariance results

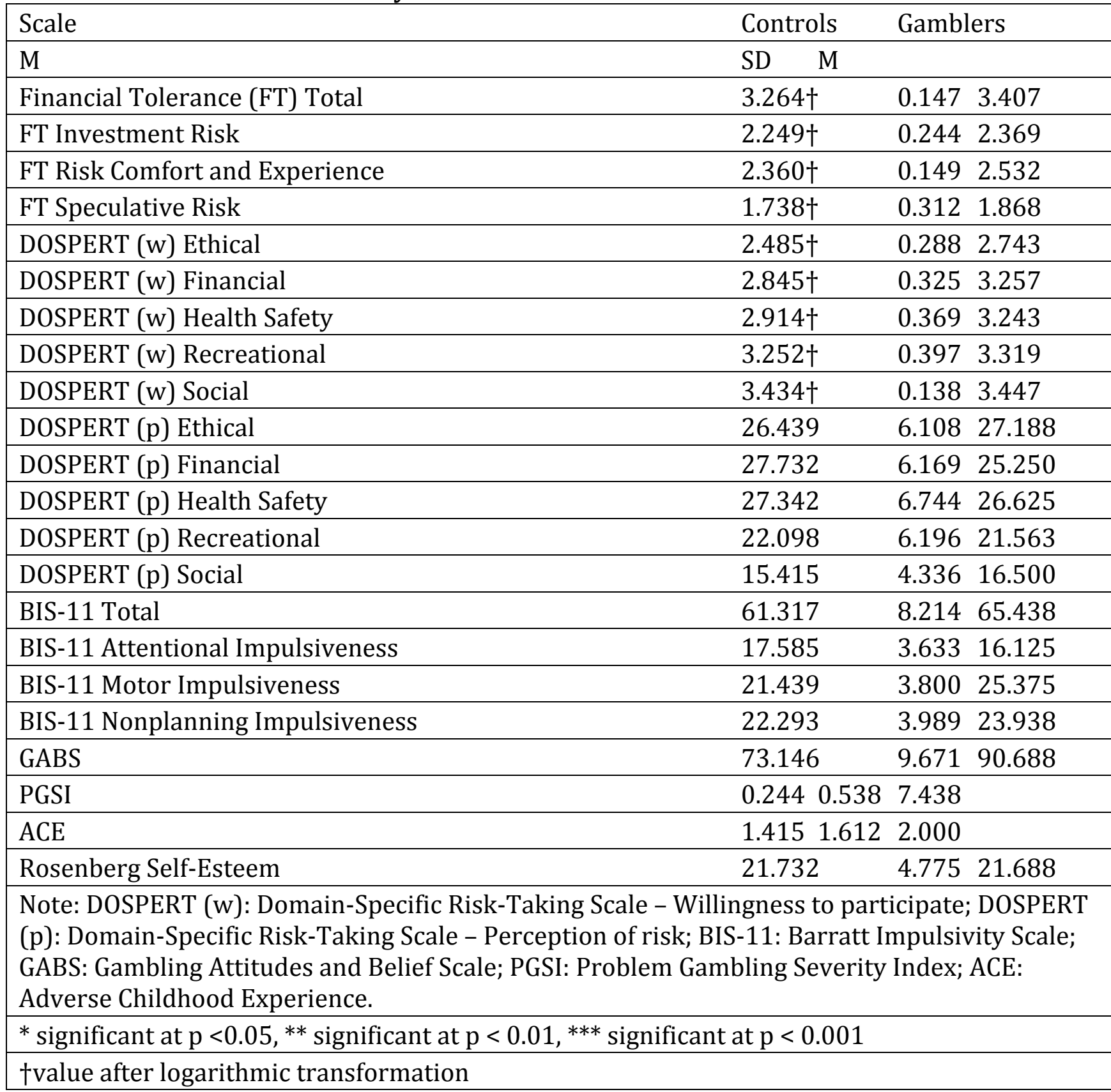

